\title{
Critical Ignition Temperatures of Wood Sawdusts
}

\section{TAKASHI KOTOYORI}

Research Institute of Industrial Safety, Ministry of Labor

5-31-1 Shiba, Minatoku, Tokyo, 108 Japan

ABSTRACT

Critical ignition temperatures were estimated for fifteen species of wood sawdust slabs, being stacked in air at normal pressure, with an adiabatic selfignition testing apparatus following a procedure. Assuming each stack to be in the form of an infinite slab of a thickness of $60.96 \mathrm{~cm}$ ( 2 feet), the temperature is estimated to range from 118 for Zelkova to $142{ }^{\circ} \mathrm{C}$ for Sitka spruce. These values are in reasonable agreement with a few real data observed on wood sawdust stacks of similar sizes. Zelkova and Western red cedar are relatively easy to ignite, meanwhile Sitka spruce and Western hemlock are relatively hard to ignite. Douglas fir and Port orford cedar are medium in ignitability.

KEY WORDS: Critical ignition temperature; wood sawdust; self-ignition; adiabatic oxidation reaction; thermal diffusivity; relative ignitability.

\section{INTRODUCTION}

Many research reports have appeared on various aspects of pyrolysis and combustion phenomena of wood or woody materials. Instances, however, have been 'only a few so far where the critical ignition temperatures of bulky stacks of wood sawdusts were actually measured. As for that point, the works by Gross et al. [1], by Akita[2], and lately by Anthony et a1. [3], by John[4] and by Schliemann[5] are quite precious.

In the present work, critical ignition temperatures of fifteen species of wood sawdust slabs, assuming each to be stacked in hot air surroundings at normal pressure, were estimated with an adiabatic self-ignition testing apparatus following a procedure.

A detailed description of the apparatus was given elsewhere[6]. So the procedure to estimate the critical ignition temperature of any stack of selfheating substance and results when the procedure was applied to wood sawdust slabs are mainly described in this report.

Wood species tested are as follows: Telaling (a Southeast Asian lumber), Meranti (ditto), Sawara cedar, Japanese cedar, Japanese red pine, Japanese cypress, Zelkova, Paulownia, Western red cedar, Douglas fir, Port orford cedar, Alaska yellow cedar, Western hemlock, Sitka spruce and Eli ayanskya (a Siberian lumber). 


\section{ASSUMPTION}

When a sample heats spontaneously at a temperature $T$, eqn. (1) holds generally under an adiabatic zeroth order assumption, based on the principle of energy conservation.

$\operatorname{c\rho } \frac{\mathrm{dT}}{\mathrm{dt}}=\Delta \mathrm{H} \cdot \mathrm{A} \exp \left[-\frac{\mathrm{E}}{\mathrm{RT}}\right]$

If we assume that the temperature rise rate, $\mathrm{dT} / \mathrm{dt}$, remains effectively constant within small temperature ranges near $T$, we can easily integrate eqn. (1) and get the following equation after taking natural logarithms on both sides of an equation obtained by the definite integral of eqn. (1).

$\operatorname{In} \Delta t=\frac{\mathrm{E}}{\mathrm{RT}}+\operatorname{In}\left[\frac{\Delta \mathrm{T} \cdot \mathrm{CP}}{\Delta \mathrm{H} \cdot \mathrm{A}}\right]$

where $\Delta \mathrm{t}$ is the time required for the sample temperature to rise from $T$ to $(\mathrm{T}+\Delta \mathrm{T})$. Equation (2) can be applied to the adiabatic self-heating curve recorded precisely, by an adiabatic self-heating process recorder such as the apparatus used here, in temperature ranges of a few degrees above T. Then the gradient, $a$, and intercept, $b$, of an empirical formula, in $\Delta t=(a / T)+b$, can be expressed as,

$a=\frac{E}{R}$

$\mathrm{b}=\ln \left[\frac{\Delta \mathrm{T} \cdot \mathrm{c} \rho}{\Delta \mathrm{H} \cdot \mathrm{A}}\right]$

respectively.

A RELATION DERIVED FROM FRANK-KAMENETSKII'S CRITICAL CONDITION FOR THERMAL IGNITION AND EQUATION (2)

Frank-Kamenetskii's critical parameter $\delta_{c}$ for thermal ignition is expressed as,

$\delta_{c}=\frac{\Delta \mathrm{H} \cdot \operatorname{Er}^{2} \mathrm{~A}}{\lambda \mathrm{RT}_{\mathrm{C}}^{2}} \exp \left[-\frac{\mathrm{E}}{\mathrm{RT}}\right]$

Frank-Kamenetskii's critical condition for thermal ignition holds on a balance between the heating process, again based on a zeroth order reaction, and the heat loss process under non-adiabatic conditions. Incidentally eqn. (2) is concerned with the heating process alone, since it stands on the adiabatic conditions. So far as the heating process is concerned, however, both equations deal with the identical slow heating process in the subcritical state prior to ignition. Therefore it can be thought that factors such as $\mathrm{E}, \mathrm{A}$ and $\Delta \mathrm{H}$ appearing in eqn. (2) and corresponding those in eqn. (5) represent the same physical quantities, respectively.

Taking natural logarithms on both sides of eqn. (5) and rearranging them gives,

$\ln \mathrm{T}_{\mathrm{c}}+\frac{(\mathrm{E} / \mathrm{R})}{2 \mathrm{~T}_{\mathrm{c}}}=\ln \mathrm{r}+\frac{1}{2} \ln \left[\frac{(\Delta \mathrm{H} \cdot \mathrm{A})(\mathrm{E} / \mathrm{R})}{\delta_{\mathrm{c}} \cdot \lambda}\right]$

substituting eqns. (3) and (4) in eqn. (6) for $(E / R)$ and $\ln (\Delta H \cdot A)$ gives,

$\ln \mathrm{T}_{\mathrm{c}}+\frac{\mathrm{a}}{2 \mathrm{~T}_{\mathrm{c}}}=\ln \mathrm{x}+\frac{1}{2}\left[\ln \left(\frac{\mathrm{a} \cdot \Delta \mathrm{T} \cdot \mathrm{c} \rho}{\delta_{\mathrm{c}} \cdot \lambda}\right)-\mathrm{b}\right]$ 
since thermal conductivity is expressed in terms of thermal diffusivity and heat capacity per unit volume, as in eqn. (8),

$\lambda=\alpha \cdot c \rho$

eventually we obtain,

$\ln T_{c}+\frac{a}{2 T_{c}}=\ln r+\frac{1}{2}\left[\ln \left(\frac{a \cdot \Delta T}{\delta_{c} \cdot \alpha}\right)-b\right]$

We see from eqn. (9) that we may dispense with direct knowledge of the individual values of $\Delta \mathrm{H}, \mathrm{E}, \mathrm{A}, \lambda$ and $\mathrm{c}$ of the substance, so far as the estimation of $\mathrm{T}$ is in question. The only data required to estimate $\mathrm{T}$ value is the thermal diffusivity associated with the material, besides data, obtained with the apparatus, such as $a, b$ and $\Delta T$. values of $r$ and $\delta$ can be assigned as desired. Methods of determining thermal diffusivity for materials are well established[7]. As a matter of course the packing density $p$ of the substance in the sample cell of the self-ignition testing apparatus and of the thermal diffusivity measuring apparatus should be as equal as possible to that in the practical conditions.

\section{STARTING PROCEDURE}

A block diagram of the apparatus used here is shown in Fig. 1. Measuring procedure for oxidatively heating substances has been described elsewhere[6], but a part of it was modified in this work because of the nature of wood sawdust.

$300 \mathrm{mg}$ of wood sawdust sample is packed in the cell that has a hole at the bottom. Next the thermocouple for measuring sample temperature is inserted into

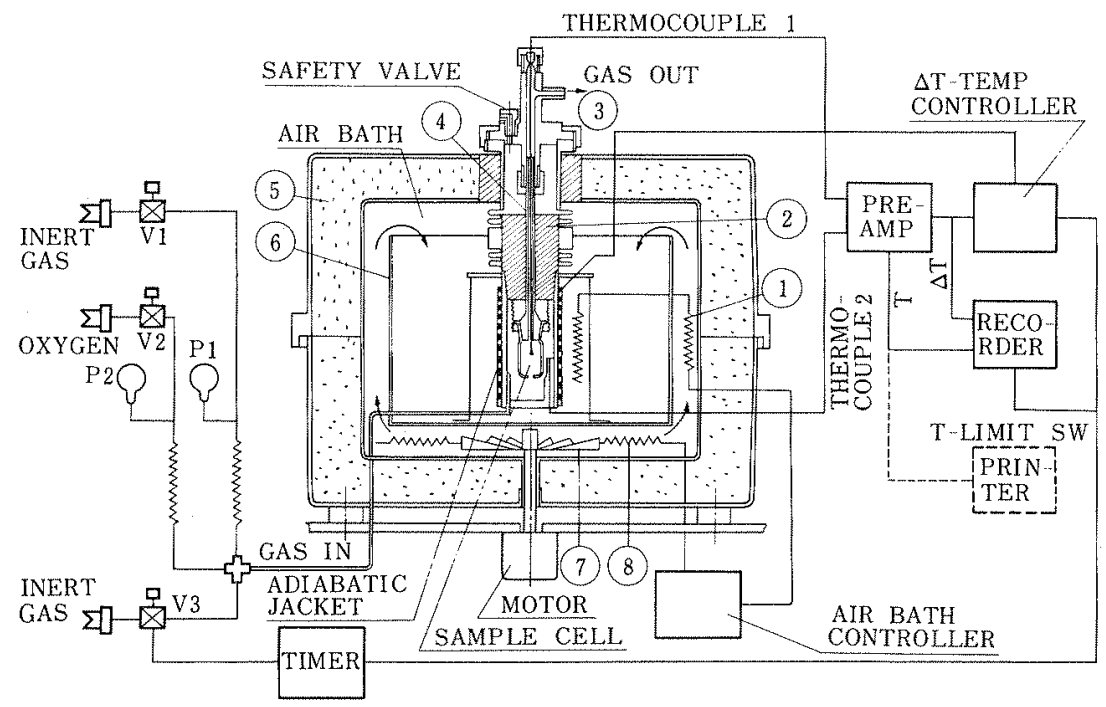

FIGURE 1. Block diagram of the adiabatic self-ignition testing apparatus. 1, Thermometer; 2, glass wool; 3, sample cell assembly; 4, silica tube; 5, glass wool; 6, wind guide plate; 7 , fan; 8 , heater. 
the sample. Then the sample cell assembly is set in the adiabatic jacket, and nitrogen gas is supplied at a rate of $2[\mathrm{ml} / \mathrm{min}]$. The initial starting temperature is selected as desired by setting a temperature dial on the air bath. Then the power is switched on, that is, bath heating is started. After that the apparatus is left for 270 minutes at the starting temperature in nitrogen atmosphere, to remove all of the moisture from wood sawdust and to establish thermal equilibrium. While moisture-removal process lasts, the measurement can not be started, since the endothermic effect due to vaporization of moisture masks the exothermic phenomenon due to oxidation reaction of the substrate. Then, zero-suppression procedure is carried out, and immediately after that, the supply of air at a rate of $2[\mathrm{~m} 1 / \mathrm{min}]$, adiabatic control and recording of the heating process are commenced.

\section{ESTIMATION PROCEDURE OF CRITICAL IGNITION TEMPERATURE OF WOOD SAWDUST}

Wood strips are first prepared by cutting some $2.5 \mathrm{~mm}$ thick slabs from visually uniform pieces of wood block of each species using a band saw. The strips are next cut into some $2.5 \mathrm{~mm}$ by $2.5 \mathrm{~mm}$ by $2.5 \mathrm{~mm}$ chips with a nipper. Chips are then pulverized using an ultra centrifugal mill and size-graded to 35 to 60 mesh by sieving.

Adiabatic oxidation heating curves of each species of wood sawdust are recorded at starting temperatures ranging from 150 to $178^{\circ} \mathrm{C}$, following the starting procedure stated above. The curves for Port orford cedar sawdust are shown in Fig. 2 as an example. In these cases it is seen that the rate of adiabatic oxidation reaction is gradually accelerated, as nitrogen atmosphere

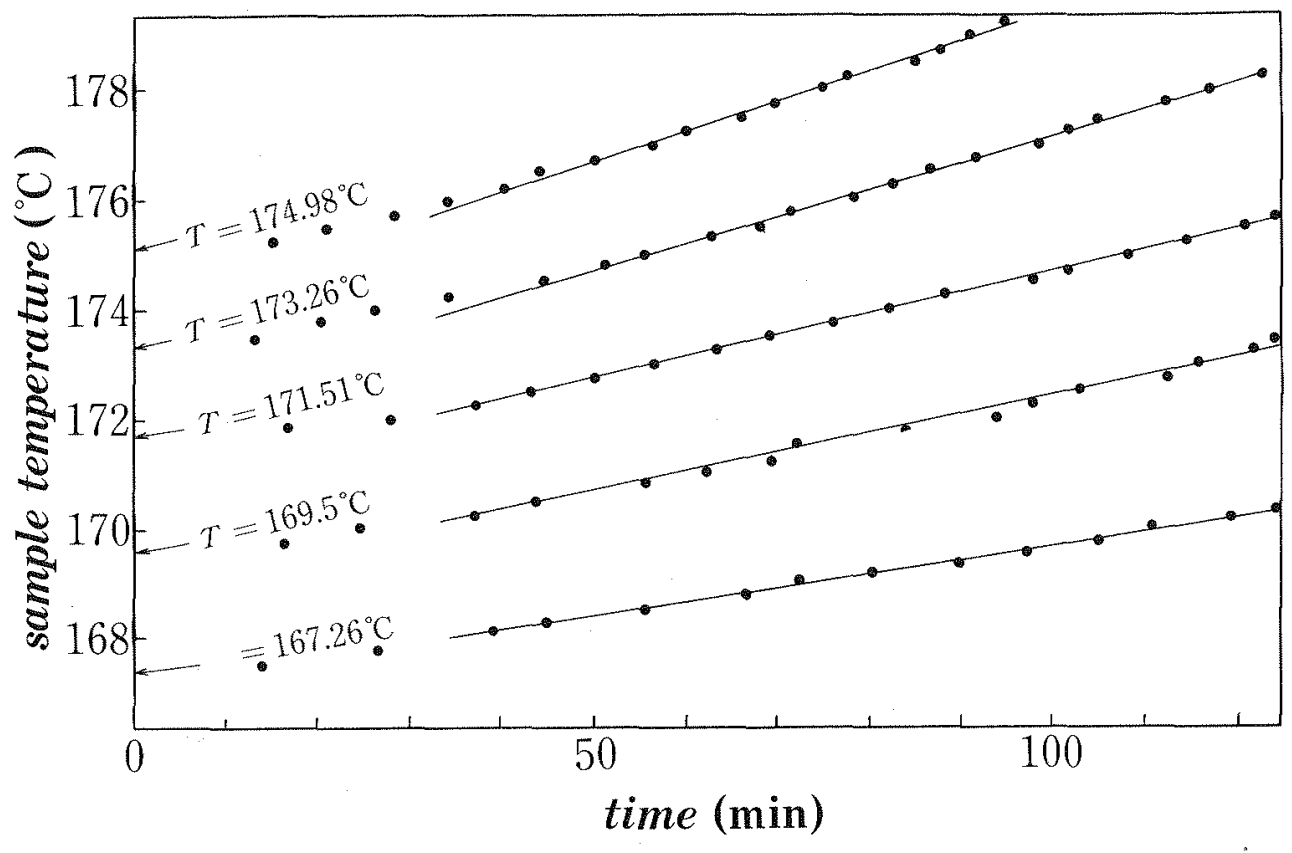

FIGURE 2. Adiabatic oxidation heating curves of Port orford cedar sawdust. 


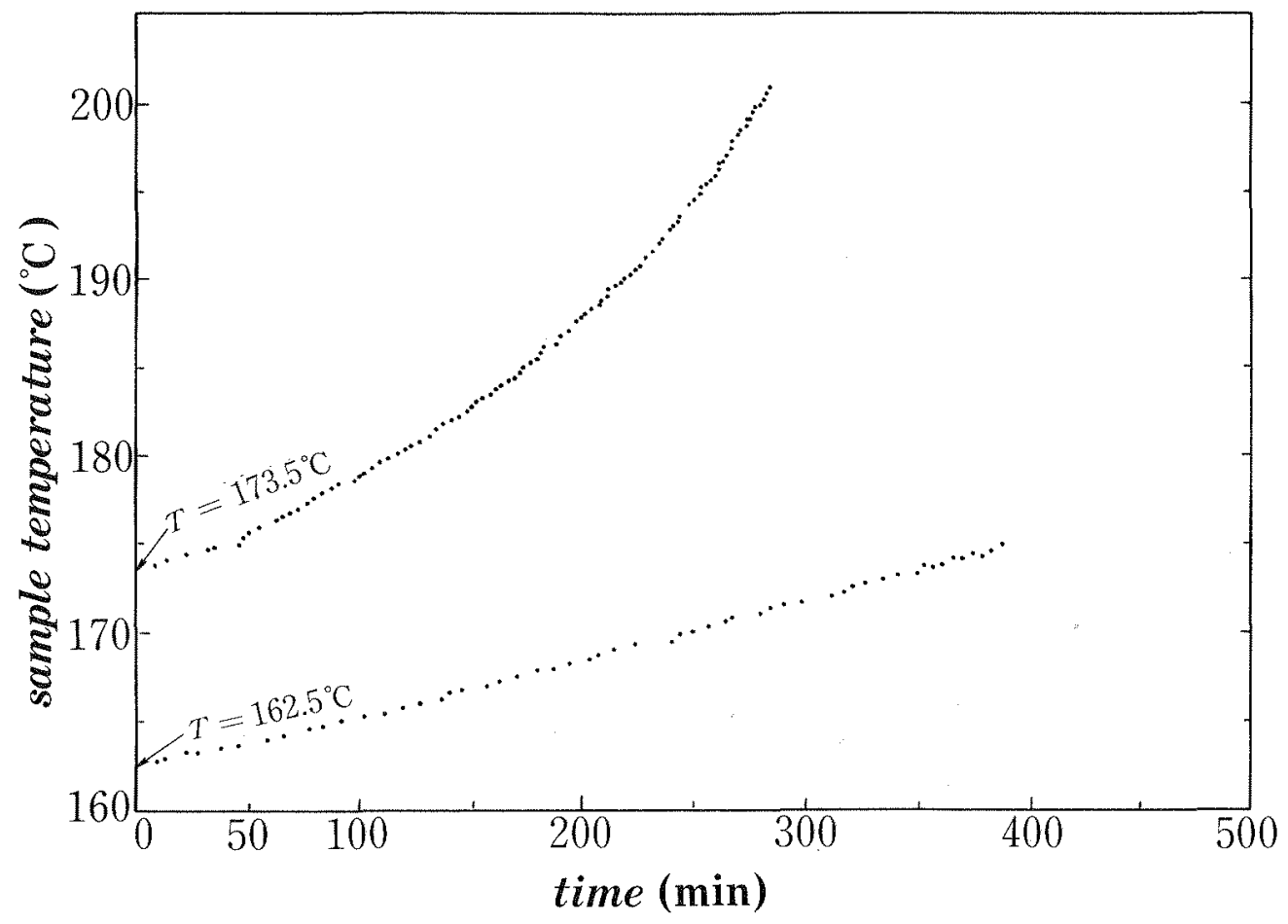

FIGURE 3. Adiabatic oxidation heating curves of Western red cedar sawdust with wider temperature increments.

around and in the sample cell is replaced by air for about 30 minutes after the start.

Adiabatic oxidation heating curves of wood sawdusts recorded with this apparatus appear in most cases approximately linear. For instance, a curve is almost linear at temperature levels of 160 to $175{ }^{\circ} \mathrm{C}$ in the case of Western red cedar sawdust, though the temperature rise rate begins to accelerate gradually at levels in excess of $180{ }^{\circ} \mathrm{C}$, as shown in Fig. 3. The same thing has been reported also by Akita[2], by Anthony et a1.[3] and by Schliemann[5]. Therefore a decision was made in this work that the gradient, $\Delta \mathrm{T} / \Delta \mathrm{t}$, of the linearly rising part of a curve was used as a physical quantity corresponding to the rate of the oxidatively heating reaction of wood sawdust.

The time, $\Delta t$ min, required for the sample temperature to rise by a $\Delta T$ value of $1.25 \mathrm{~K}$ is determined on each heating curve. Then $\ln \Delta t \mathrm{vs} .1 / \mathrm{T}$ plot is made for each species. The entire plots for fifteen species of wood sawdust are given in Fig. 4. We can see roughly from Fig. 4 the relative liability of these wood sawdusts to heat oxidatively, or to ignite ultimately.

Values of coefficients, $a$ and $b$, of eqn. (2) are determined from these plots by the least-squares method with a computer and are listed in TABLE 1 . 


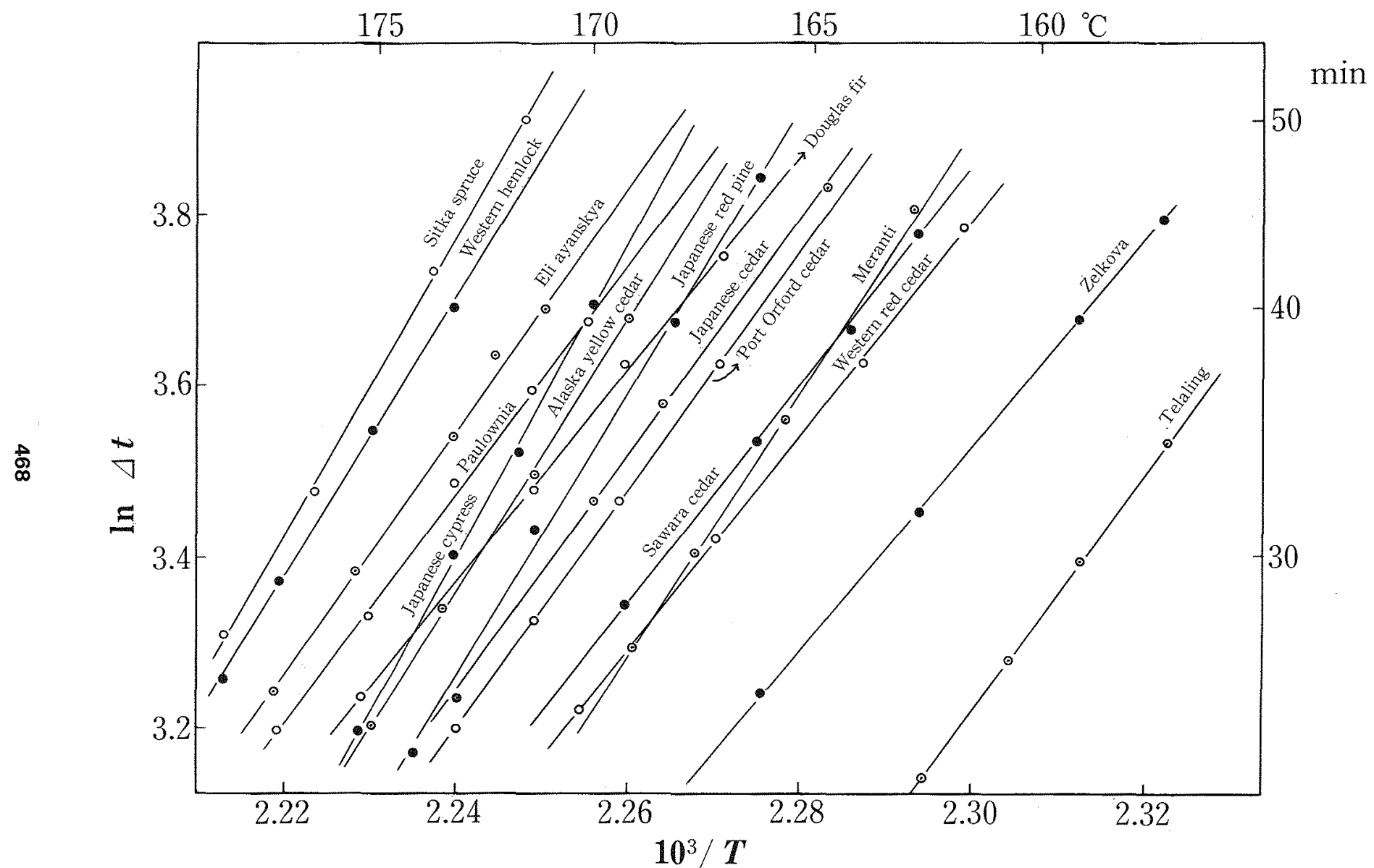

FIGURE 4. The entire In $\Delta t$ vs. $1 / T$ plots for fifteen species of wood sawdust. 
TABLE 1 Adiabatic experimental parameters of slow oxidation reaction and critical ignition temperatures of 15 species of wood sawdust, when each stacked in a slab, $60.96 \mathrm{~cm}$ thick.

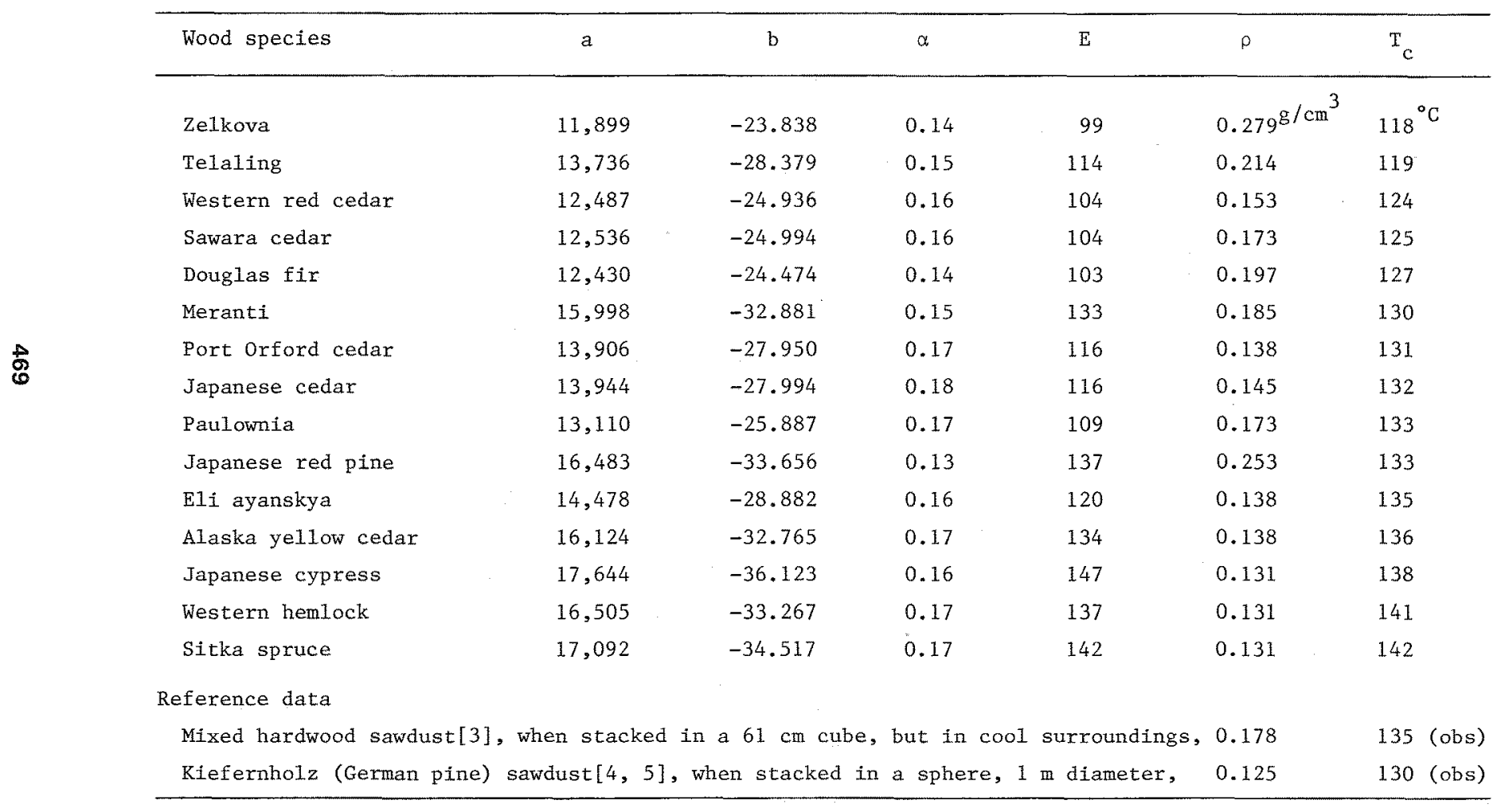


The $\alpha$ value of wood sawdust was measured at room temperature and at $100{ }^{\circ} \mathrm{C}$ with the stepwise heating method developed by Araki et a1.[7]. Values at both temperatures were much the same for each species, so the value is given in TABLE 1 as an arithmetical mean, respectively.

The form of the stack was assumed to be an infinite slab, which has a $\delta_{c}$ value of 0.88 , of a thickness of $60.96 \mathrm{~cm}$ (2 feet), which is equal to $2 \mathrm{r}$.

Substituting these data in eqn. (9), $T$ values are obtained and are presented in TABLE 1. Wood species are arranged in order, wood sawdust of high critical ignition temperature being listed near the bottom.

\section{RESULTS AND DISCUSSION}

A possibility of heat loss due to air flow in the sample cell could not be ignored, though it would be almost perfectly covered by the adiabatic control. If that effect were serious, the true $T$ value might be several degrees lower than the one determined by the procedure. ${ }^{C}$ Furthermore there might be some uncertainty in $1 n \Delta t$ vs. $1 / T$ plots, though it would be considerably compensated by the leastsquares method. As for that problem, to increase the number of the point on each plot from 4 or 5 to 10 , e.g., may be helpful to increase the certainty of the plot. It is also not very pleasant that we can not make the packing density constant for each species because of the nature of wood sawdust.

For a11 those problems, T values of wood sawdust slabs estimated by calculation, following the procedure introduced above, agreed in the result reasonably with a few real data observed on stacks of similar sizes, though the species are different from those used in this work[3, 4, 5]. It thus appears that those problems anticipated above are practically negligible with wood sawdusts, at least. Then we can say that the procedure is applicable to estimate relatively and quantitatively the ignitability of any stacks of wood sawdusts.

Assuming wood sawdust to be stacked in a form of infinite slab at a thickness of $60.96 \mathrm{~cm}$ ( 2 feet), the $T$ value is estimated to range from 118 for Zelkova to $142{ }^{\circ} \mathrm{C}$ for sitka spruce. If the slab is $20.32 \mathrm{~cm}$ ( 8 inch) thick, the value is estimated to range between 147 for Telaling to $167^{\circ} \mathrm{C}$ for Sitka spruce. Zelkova and Western red cedar are relatively easy to ignite, meanwhile sitka spruce and Western hemlock are relatively hard to ignite. Paulownia may also belong under a category that is hard to ignite. Douglas fir and Port Orford cedar are medium in ignitability.

The oxidatively heating process of wood sawdusts proceeds showing an almost linear temperature rise rate in temperature ranges up to about $180{ }^{\circ} \mathrm{C}$ under adiabatic conditions.

The relative liability of wood species to heat oxidatively is scarcely recognized by thermal analysis such as TG-DTA, meanwhile it can be clearly distinguished from one species to another under adiabatic conditions.

Wood is a natural product and its composition is not homogeneous, so $T$ values listed in TABLE 1 are by no means of absolute character. Nevertheless the author thinks that, although there may exist still some uncertain factors such as those stated at the beginning of this chapter, a procedure to estimate $\mathrm{T}$ values of wood sawdust stacks has been fundamentally established. The ignitabifity of any self-heating substances can be relatively and quantitatively determined by applying the critical ignition temperature as the criterion. So it would be interesting to see if the procedure is applicable also to other self-heating 
substances.

\section{SYMBOLS USED}

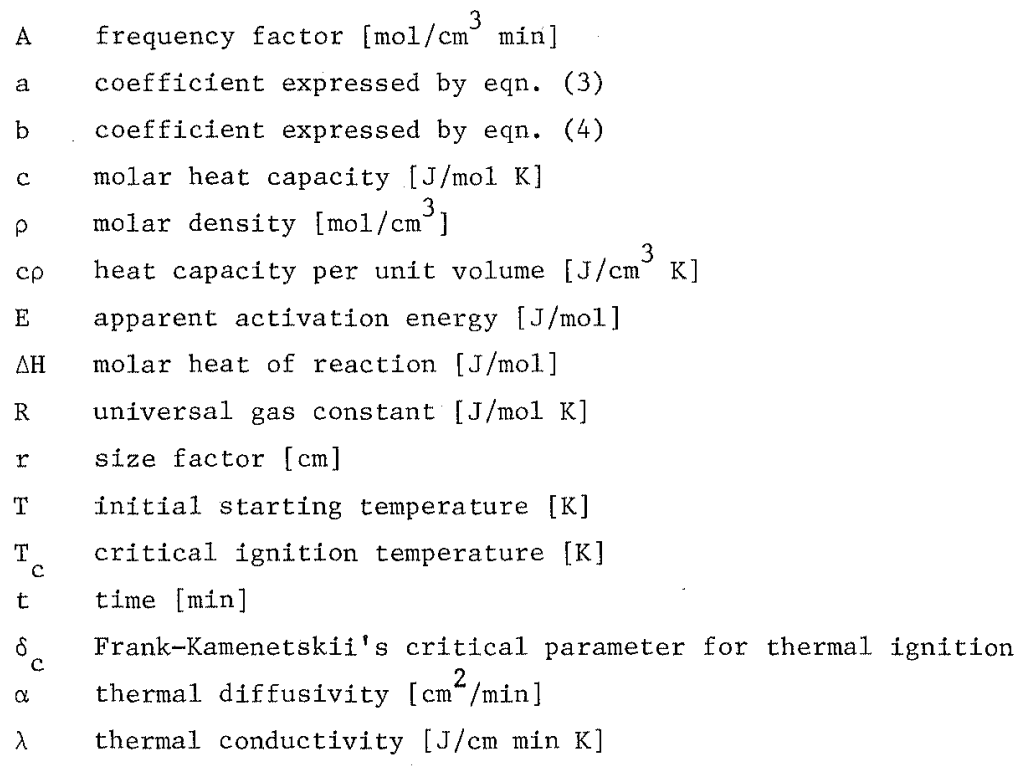

\section{REFERENCES}

1. Gross, D. and Robertson, A.F.: "Self-Ignition Temperatures of Materials from Kinetic-Reaction Data," I. Research Nat1. Bur. Standards, 61: 413-417, 1958.

2. Akita, K.: "Studies on the Mechanism of Ignition of Wood," Rep. Fire Research Inst. Japan, 9: 1-106, 1959.

3. Anthony, E. J. and Greaney, D.: "The Safety of Hot Self-Heating Materials," Combustion Science and Technology, 21: 79-85, 1979.

4. John, R.: "Zur Selbstentzlindung von Holz. Aufheizphase und freiwerdender Warmestrom," in Origin and Spread of Fire (1atest state of research) - No. 1, 4 th Internat1. Fire Protection Seminar - Zurich, 59-84, Brand-VerhutungsDienst fur Industrie und Gewerbe, Zurich, 1973.

5. Schliemann, H.: "Die Anwendung der Differential-Thermoanalyse (DTA) zur Einschätzung des Selbstentzlindungsverhaltens von Holz," Holzindustrie, 30: 5, $140-142,1977$.

6. Kotoyori, T. and Maruta, M.: "An Adiabatic Self-Ignition Testing Apparatus," Thermochimica Acta, 67: $35-44,1983$.

7. Araki, N.: "Measurements of Thermophysical Properties by a Stepwise Heating Method," Internat1. J. of Thermophysics, 5: 1, 53-71, 1984. 


$$
\text { th }
$$

